\title{
El funcionario interino: entre la temporalidad y la estabilidad
}

\section{The interim civil servant: between temporality and stability}

\author{
Jesús Fuentetaja Pastor \\ Universidad Nacional de Educación a Distancia - UNED (España) \\ ORCID: https://orcid.org/0000-0002-2049-9393 \\ jfuentetaja@der.uned.es
}

\section{NOTA BIOGRÁFICA}

Catedrático de Derecho Administrativo (UNED). Sus principales líneas de investigación son el Derecho Administrativo Europeo y el Derecho de la Función Pública. Es autor de diversas publicaciones en materia de Función Pública.

\section{RESUMEN}

Aunque la situación jurídica de los funcionarios interinos se caracteriza por su temporalidad, la regulación y la gestión de esta clase de empleado público generan situaciones de estabilidad no sólo al limitar la potestad de la Administración para finalizar las relaciones jurídicas interinas sino también al favorecer la prolongación de su duración.

\section{PALABRAS CLAVE}

Funcionario interino; temporalidad; estabilidad; cese.

\begin{abstract}
Although the legal status of interim civil servants is characterized by their temporary nature, the regulation and management of this class of public employee generate situations of stability not only by limiting the authority of the Administration to remove interim civil servants but also by increasing the duration of their legal relationships.
\end{abstract}

\section{KEYWORDS}

Interim civil servant; temporary nature; stability; removal.

\section{SUMARIO}

I. TEMPORALIDAD Y ESTABILIDAD EN LA FUNCIÓN PÚBLICA. II. LA TEMPORALIDAD DEL FUNCIONARIO INTERINO. III. LA ESTABILIDAD DEL FUNCIONARIO INTERINO. 1. "ESTABILIDAD CAUSAL»: EL CESE DE LOS FUNCIONARIOS INTERINOS. 1.1. LA CAUSALIZACIÓN DE LOS CESES. 1.2. TIPIFICACIÓN DE LAS CAUSAS DE CESE DE LOS FUNCIONARIOS INTERINOS. 1.3. OBJETIVACIÓN DE LAS CAUSAS DE CESE DE LOS FUNCIONARIOS INTERINOS. 1.4. CONTROL DEL CESE POR DESAPARICIÓN DE «URGENCIA Y NECESIDAD». 2. «ESTABILIDAD SUBJETIVA»: LA DESVINCULACIÓN DEL FUNCIONARIO INTERINO DEL PUESTO DE TRABAJO. 3. «ESTABILIDAD DISCONTINUA»: LAS BOLSAS DE TRABAJO. 4. «ESTABILIDAD TUITIVA»: PROTECCIÓN DE LA RELACIÓN COMO CRITERIO INTERPRETATIVO. IV. CONCLUSION. REFERENCIAS BIBLIOGRÁFICAS. 


\section{TEMPORALIDAD Y ESTABILIDAD EN LA FUNCIÓN PÚBLICA}

Estabilidad y temporalidad no son conceptos antitéticos, por mucho que una de las acepciones del primero suponga lo contrario del segundo. La lucha por la estabilidad, en su dimensión de inamovilidad en la condición funcionarial, constituyó de hecho uno de los ejes que articularon la evolución institucional de la Función Pública contemporánea, evitando los ceses arbitrarios o discrecionales y conformando un régimen jurídico que protegía al funcionario de injerencias políticas en el ejercicio de sus funciones.

La estabilidad puede constituir tanto una situación jurídica como meramente fáctica, según que sea pretendida directamente por la norma o se derive de la forma de aplicación o de inaplicación de ésta. Como decíamos, lo contrario de estabilidad no es temporalidad, sino más bien precariedad de la relación jurídica en la medida en que una de las partes pueda producir su alteración o extinción con más o menos facilidad sustantiva y procedimental. Por ello, la estabilidad es una propiedad gradual. En este sentido, la relación funcionarial no es plenamente estable en su contenido al poder ser modificada unilateralmente por el Legislador y por la Administración, tal y como es propio de la naturaleza estatutaria del vínculo ${ }^{1}$. Y tampoco lo es en su duración, no sólo porque su decurso normal conduzca a un término natural (jubilación por alcanzar el período máximo de servicio activo posible) sino también porque la norma prevé circunstancias excepcionales cuyo acaecimiento determina la finalización anticipada de la relación (muerte, renuncia, sanción de separación, pena de inhabilitación, jubilación por incapacidad permanente, pérdida de nacionalidad).

Lo importante, desde el punto de vista de la estabilidad de la relación, es la configuración objetiva de las causas de finalización de ésta, limitando o eliminando incluso la discrecionalidad o el margen de apreciación de la Administración en su concurrencia. Por eso, la estabilidad no es una característica tampoco ajena a los funcionarios temporales, en la medida en que las causas de finalización de su relación se objetiven normativamente.

Es evidente que la mayor estabilidad jurídica derivada de la regulación de las relaciones funcionariales temporales genera fácticamente una mayor duración de las mismas. Pero el juicio de la temporalidad no se mueve tanto en el plano de la dinámica de dichas relaciones como en el de la regulación estática de las normas al configurarlas. No obstante lo cual, la temporalidad de las relaciones funcionariales se debe deducir más de su concepción institucional que de la explicitación normativa. No existe, en efecto, en la normativa una previsión explícita y directa sobre la duración de aquellas relaciones -a diferencia de las relaciones laborales en la Administración- simplemente porque no es necesario, aunque del funcionario de carrera se predique su "carácter permanente» (9.1 TREBEP) y del funcionario interino ni siquiera lo contrario, pues en su propia denominación va ínsita su temporalidad, por mucho que a continuación su articulación jurídica no termine de garantizar técnicamente dicha temporalidad.

En efecto, los funcionarios interinos son funcionarios temporales porque tanto los presupuestos como las causas de la relación son de duración determinada, sin perjuicio de que la regulación y la aplicación de la normativa hayan generado duraciones indeterminadas cuya prolongación en el tiempo pueda ser considerada larga, excesiva o, en virtud del Derecho europeo, abusiva. Sin embargo, estas duraciones excesivas o abusivas son consecuencia no sólo de la vulneración de las normas encaminadas a prevenirlas sino también de técnicas de regulación, de interpretación y de gestión informadas por el objetivo aparentemente paradójico de garantizar una mayor estabilidad y duración de las interinidades funcionariales.

El objetivo de este trabajo no es el de analizar las consecuencias de las duraciones excesivas de las relaciones funcionariales interinas ${ }^{2}$, consecuencias que han dado lugar a la creación de dos categorías jurídicas con contenidos y orígenes diferentes -en el Derecho interno, el «funcionario interino de larga duración»3; $y$, en el Derecho europeo, el "abuso» ${ }^{4}$ de los funcionarios interinos-, sino el de reflexionar sobre las causas normativas, jurisprudenciales y de gestión que generan o propician esas consecuencias.

1 LÓPEZ BENÍTEZ, M.: "Concepto y clases de empleados públicos", en Derecho Administrativo. Tomo IV (coords. Izquierdo, M. y López Benítez, M.), Tecnos 2019, pág. 57.

2 Vid., al respecto, FUENTETAJA, J.: "La utilización abusiva de los funcionarios interinos ante el derecho europeo: entre la transformación en funcionarios de carrera y el derecho a indemnización" en Revista de administración pública, núm. 212, 2020, págs. 201230; SÁNCHEZ MORÓN, M.: "La consagración del funcionario interino indefinido", en Revista de Administración Pública, núm. 208, 2019, págs. 223-238.

Sobre el origen y contenido de esta categoría, vid. SÁNCHEZ MORÓN, M., Régimen jurídico de los funcionarios interinos, Thomson Reuters Aranzadi, 2020, págs. 41-44.

4 FUENTETAJA, J., Función Pública y Derecho europeo, Civitas, 2018. 


\section{LA TEMPORALIDAD DEL FUNCIONARIO INTERINO}

La naturaleza temporal del funcionario interino constituye, sin duda alguna, su característica más esencial $^{5}$, diferenciándolo cualitativamente del funcionario permanente de carrera. En última instancia, toda la relación jurídica interina viene conformada por este elemento de temporalidad: desde su propio nacimiento, a través de procedimientos ágiles ${ }^{6}$ y menos rigurosos y estrictos que los encaminados a seleccionar funcionarios permanentes, hasta las causas que determinan el cese de la relación, completamente diferentes a las previstas para los funcionarios de carrera, pues aunque las aplicables a éstos también rigen para los funcionarios interinos, lo singular de la extinción de la relación interina es la finalización de las causas que permitieron en su día el nombramiento.

$Y$ es que la causa del nombramiento - «circunstancias», según la terminología legal del art. 10.2 del Texto Refundido del Estatuto Básico del Empleado Público de 2015- es intrínsecamente temporal: vacante con inherente vocación a ocupación con carácter permanente; sustitución transitoria de titular del puesto; o necesidades temporales (programas y acumulación de tareas), cuya imprecisión objetiva se soluciona fijando convencionalmente una duración precisa.

De ahí que la relación sea temporal, pues finalizada la causa del nombramiento (ocupación de vacante por nuevo titular; reingreso al servicio del titular del puesto sustituido transitoriamente; expiración del plazo de las interinidades por funciones temporales), el funcionario deba ser cesado. Cuestión diferente es que la propia configuración de estas causas de nombramiento propicie duraciones indeterminadas de la relación interina que, incluso perfectamente legales, produzcan situaciones fácticas con relevancia jurídica según se califiquen como «de larga duración» o «abusivas».

En este sentido, la duración de la relación funcionarial interina habría que valorarla tanto por su carácter abusivo -lo que implica un juicio subjetivo de la intencionalidad fraudulenta por la Administración al recurrir a relaciones temporales para necesidades permanentes- como, en su caso, por su larga duración -lo que supone la consideración objetiva del carácter desproporcionado de la duración de la interinidad al excederse temporalmente de lo adecuado para la duración del fin para el que se recurrió a la misma-.

Así, una duración abusiva de la relación interina puede deducirse de la inactividad de la Administración al no aplicar los elementos normativos reglados que determinan la finalización de la relación interina: desde los automáticos términos temporales de duración de los supuestos de funcionarios interinos de programa o de acumulación de tareas a la obligación de incorporar las vacantes en las que son nombrados los funcionarios interinos a la siguiente Oferta de empleo público posible (10.4 TREBEP). Por su parte, la sustitución del funcionario de carrera puede comprender situaciones administrativas -en sentido lato y estricto- que amparen relaciones interinas con lustros de prolongación, si pensamos simplemente en casos de funcionarios que permanecen en la vida política durante mandatos parlamentarios encadenados durante decenios. En estos casos, obviamente, la duración de la interinidad podría describirse objetivamente como prolongada y valorarse incluso subjetivamente como excesiva, pero no por ello calificarse o descalificarse jurídicamente como abusiva.

En cualquier caso, la caracterización esencial de las relaciones funcionariales interinas por su temporalidad debe comprenderse desde las diferentes medidas que contribuirían a dotar a aquellas de mayor estabilidad.

\section{LA ESTABILIDAD DEL FUNCIONARIO INTERINO}

La temporalidad propia de las relaciones funcionariales interinas puede verse desvirtuada, matizada o incluso eliminada, tanto mediante una gestión incorrecta de los recursos humanos como a través de mecanismos normativos o técnicas de gestión y de aplicación que se encaminan a garantizar una estabilidad a los funcionarios interinos, ya sea en su acepción de permanencia de la relación, ya en cuanto que limitación de la discrecionalidad de la Administración para poner fin a aquella.

En efecto, además de la desvirtuación de la temporalidad de las relaciones interinas por la directa inaplicación de las medidas normativas previstas para garantizarla ${ }^{7}$, lo cierto es que el sistema ha ido introduciendo

\footnotetext{
5 STS 14 abril 1997 (Rec. 2674/1994).

6 Art. 10.2 TREBEP.

7 Podría hablarse incluso de una cierta «estabilidad fáctica» de los funcionarios interinos derivada del mero incumplimiento de las medidas preventivas garantizadoras de la temporalidad de la relación. La incorrecta gestión de los funcionarios interinos en las Ad-
} 
técnicas que indirectamente garantizan una relativa estabilidad a las relaciones o a las situaciones interinas. La más importante de ellas, de carácter normativo, consiste en la causalización de los ceses («estabilidad causal»), de manera que se circunscriben las posibilidades de extinción de la relación por la Administración, aunque resulta igualmente trascendente la admisión de la pervivencia de la relación funcional interina desvinculada del puesto de trabajo, lo que implica además una evolución en la concepción del funcionario interino en cuanto que estatus subjetivo semejante al de los funcionarios de carrera («estabilidad subjetiva»).

Particular atención merecen también dos técnicas, la primera de gestión, relativa a la discontinuidad de las relaciones interinas derivadas de la existencia de bolsas o listas de interino(«estabilidad discontinua» o indirecta); y la segunda de carácter jurisprudencial, al erigir la protección de la relación funcionarial como criterio de interpretación de la normativa reguladora del cese («estabilidad tuitiva»), como en el caso de la conversión de las relaciones interinas para evitar su extinción.

Por último, no se abordarán en este trabajo otras técnicas que se han utilizado asimismo para garantizar la mayor continuidad o estabilidad a los funcionarios interinos, como los acuerdos de reserva de vacantes para nombramientos interinos ${ }^{8} \mathrm{o}$ la fijación de plazos determinados para las relaciones interinas ${ }^{9}$, independientemente incluso de la subsistencia de su necesidad, por no hablar de la respuesta del sistema para estabilizar o consolidar las relaciones interinas mediante la transformación de éstas a través de procesos selectivos específicos ${ }^{10}$.

\section{1. «Estabilidad causal»: el cese de los funcionarios interinos}

\subsection{La causalización de los ceses}

En lo que respecta a la causalización de los ceses, se trata de una de las grandes novedades que el Estatuto Básico del Empleado Público de 2007 introdujo en la figura del funcionario interino. En realidad, como hemos visto, el Estatuto incorporó directamente las causas de nombramiento, de cuya finalización derivan indirectamente las causas de cese. Así, el Estatuto Básico establece que «[e]l cese de los funcionarios interinos se producirá, además de por las causas previstas en el artículo 63 , cuando finalice la causa que dio lugar a su nombramiento». De esta manera, el Tribunal Supremo ${ }^{11}$ ha podido distinguir «causas de cese comunes», referidas a todo funcionario público, y «causas específicas», que son las relacionadas con la causa que motivó el nombramiento del funcionario interino y que, en última instancia, son genuinas de esta figura.

Hay que tener en cuenta que tradicionalmente el nombramiento de funcionarios interinos se justificaba y amparaba exclusivamente por la urgencia y necesidad de la ocupación de puestos. Aunque se trata de

ministraciones Públicas se ha manifestado en la inaplicación de previsiones normativas encaminadas precisamente a evitar la duración desproporcionada de las relaciones interinas. Tal es el caso de los nombramientos de funcionarios interinos sobre vacantes. La propia existencia de una vacante es una anomalía organizativa, pues los puestos tienen vocación de ser ocupados y desempeñados por quienes sean sus titulares a resultas de procedimientos selectivos (funcionarios permanentes de nuevo ingreso) o de provisión (funcionarios permanentes ya al servicio de la Administración). Por ello, el nombramiento de un funcionario interino en un puesto vacante es una solución transitoria. Para evitar que esta transitoriedad se prolongue indebidamente, el art. 10.4 del TREBEP obliga a la Administración a incorporar la plaza vacante desempeñada interinamente a la primera Oferta de Empleo Público posible, de manera que se desencadene automáticamente el mecanismo que aboca a la ocupación definitiva del puesto por un funcionario de nuevo ingreso. El tenor literal de la Ley es terminante, pero no establece consecuencia jurídica alguna al incumplimiento, por parte de la Administración, de dicha obligación. No obstante, esta cautela normativa puede y suele quedar vaciada de eficacia por el simple expediente de la inacción de la Administración, al no cumplir su obligación de incorporar la vacante en cuestión a la correspondiente Oferta de Empleo Público. Con esta práctica, los nombramientos de funcionarios interinos sobre vacantes pueden durar lustros. No obstante, los Tribunales han empezado a extraer las consecuencias del citado precepto y no han dudado en anular una oferta de empleo público por no respetarlo: Vid. al respecto, SÁNCHEZ MORÓN, M.: "Informe jurídico sobre el deber de las Administraciones Públicas de incluir en la oferta de empleo público las plazas vacantes ocupadas por personal interino o temporal y publicar en plazo las correspondientes convocatorias de selección", en Revista de Administración Pública, núm. 187, enero-abril 2012, págs. 379-395.

8 Reputados ilegales: STSJ Islas Canarias, 31 octubre 2000.

9 STSJ Madrid, 9 febrero 2011 (Rec. 207/2009).

10 Vid. NAVARRO NIETO, F.: "Los planes de estabilización del empleo temporal en el Estatuto Básico del Empleado Público", en Temas laborales: Revista andaluza de trabajo y bienestar social, núm. 103, 2010, págs. 67-98; ROQUETA BUJ, R.: "Los procesos de estabilización del empleo temporal en las administraciones públicas", en Revista de Derecho Administrativo vLex, núm. 1, 2020, págs. 9-45; BOLTAINA, X.: "La estabilización de personal temporal e interino para el 2020 con Presupuestos Generales del Estado prorrogados", en La administración práctica: enciclopedia de administración municipal, núm. 3, 2020, págs. 47-56; BOLTAINA, X.: "Los procesos selectivos «blandos» y sus efectos sobre la profesionalización del empleo público”, en Revista Vasca de Gestión de Personas y Organizaciones Públicas, núm.. Extra 2, 2018, págs. 140-155.

11 STS de 20 de enero de 2010 (Rec. 2677/2017). 
conceptos jurídicos indeterminados, expresan una excepcionalidad caracterizada por la transitoriedad de las circunstancias. Por ello, tanto la urgencia como la necesidad vendrán cualificadas por su dimensión coyuntural y, por ende, temporal. $Y$ aunque no resulte sencillo apreciar que ya no concurren en una determinada situación, tanto la Administración como los Tribunales no dejaban de poner fin a los nombramientos interinos cuando desaparecía la urgencia y la necesidad que justificaron el nombramiento inicial ${ }^{12}$. En consecuencia, la cláusula general de «urgencia y necesidad» que ampara la existencia de funcionarios interinos implica ya de por sí una temporalidad, si bien su carácter impreciso determina que por sí sola permita el abuso tanto en la prolongación de un nombramiento como en la concatenación de relaciones sucesivas.

De ahí la importancia de la concreción de las «circunstancias» que explicita hoy día el Estatuto Básico del Empleado Público, y que no dejan de ser una exteriorización de la «urgencia y necesidad» general que ampara con carácter general la existencia de los funcionarios interinos. En este sentido, la legislación básica ha extraído las consecuencias ínsitas a esa cláusula general, pero con la virtualidad de la exhaustividad del elenco, poniendo coto así al abuso indiscriminado en el nombramiento cuantitativo y cualitativo de este personal. A partir de ahora, la Ley ha limitado considerablemente la discrecionalidad de los ceses de funcionarios interinos por cuanto, al prever las causas de nombramientos y, por tanto, de ceses, la justificación de éstos en la mera desaparición de los presupuestos de «urgencia» y «necesidad» queda reducida, aportando una mayor seguridad jurídica a la duración de las relaciones interinas.

\subsection{Tipificación de las causas de cese de los funcionarios interinos}

La causalización legal de los ceses implica la necesidad de tipificación de las causas de éstos. En efecto, la tipificación de las causas de cese -aunque sea indirectamente por finalización de las causas de nombramiento- es imprescindible para garantizar los derechos de los funcionarios interinos. La interinidad no es precariedad de derechos. Ciertamente la normativa y la jurisprudencia han ido explicitando el régimen jurídico de los funcionarios interinos. Y en éste cobra particular importancia el derecho al mantenimiento de la relación, por mucho que la misma sea intrínsecamente temporal. El funcionario interino tiene derecho al mantenimiento de su relación mientras dure la causa que la generó y mientras permanezcan inalterados los presupuestos de la misma (urgencia y necesidad). Y este derecho -como cualquier otro que la normativa le reconozca- sólo puede ser limitado legalmente. Así lo señala el Tribunal Constitucional al señalar que «el nombramiento como funcionario interino confiere al nombrado unos derechos de los que no puede ser privado sino por las causas legalmente establecidas y no por causas no previstas al efecto» (STC 20/2001, de 29 de enero).

Por eso, no son válidas causas de cese no previstas en la norma, como el caso de la mera convocatoria del proceso selectivo conducente a la selección de funcionarios de nuevo ingreso para la ocupación de vacantes o de la no participación del funcionario interino de vacante en el proceso selectivo convocado para cubrir la misma ${ }^{13}$.

Además de la tipificación de las causas de cese también es necesario destacar que dicha tipificación debe hacerse mediante normas con rango de ley y no mediante actos, sean los de nombramiento, sean las bases de una convocatoria de selección ${ }^{14}$. Y ello porque la temporalidad de la relación interina y el hecho subsiguiente de negación del derecho de estabilidad o permanencia no implica que el funcionario interino no tenga derecho a la permanencia de su relación laboral mientras no concurra causa de cese, por lo que éstas deben estar previstas en la ley, pues la reserva de ley garantizaría que ese elemento esencial del estatuto del régimen funcionarial interino no queda a la libertad de la Administración ni en su configuración normativa vía reglamento ni menos aún -como decíamos- en su aplicación concreta vía actos de nombramiento o directamente de cese.

\subsection{Objetivación de las causas de cese de los funcionarios interinos}

Por otra parte, la causalización de los ceses de los funcionarios interinos contribuye a la mayor estabilidad de éstos por cuanto las causas de cese se objetivan por su vinculación con las causas de nombramiento

12 SSTS de 12 de mayo de 1986, de 14 de abril de 1997, de 12 de enero de 1998 o de 23 de septiembre de 2005

13 STSJ País Vasco, 9 diciembre 2010 (Rec. 639/2008).

14 STSJ Aragón, 16 abril 2020 (Rec. 317/2018): «La regulación de las causas de cese y remoción de los funcionarios no puede ser, con carácter general, objeto de un acto como una convocatoria para acceso a una bolsa de trabajo, en este caso para provisión como interinos de puestos reservados a estos funcionarios de Administración local con habilitación de carácter nacional». 
y con los presupuestos de la relación jurídica. En efecto, las causas de cese de los funcionarios interinos se configuran objetivamente por referencia a hechos objetivos determinantes de la extinción de la relación ${ }^{15}$. Tampoco se vinculan las causas de cese a las condiciones subjetivas del funcionario interino. Así, el hecho de ocupación del puesto por funcionario de carrera es causa de cese, independientemente de la mejor adecuación o capacitación del funcionario interino para su desempeño ${ }^{16}$.

Singular es el caso de cesar al funcionario interino por no presentarse a un proceso de estabilización o consolidación o por no superar el mismo ${ }^{17}$, desvinculándolo por tanto de las causas que justificaron el nombramiento o los presupuestos fácticos y jurídicos de la relación. En el primer supuesto (cese por no presentarse a un proceso selectivo de consolidación), el cese sería consecuencia bien del incumplimiento de una obligación que la norma le habría impuesto (donde el carácter sancionador de la medida invalidaría el cese), bien del cumplimiento de una condición resolutoria incluida en el nombramiento.

En el segundo supuesto (no superación del proceso selectivo), nos encontraríamos de nuevo ante una condición resolutoria de la relación funcionarial interina.

Pero como señalábamos en el planteamiento de la cuestión, lo importante es que el cese se vincula a hechos ajenos por completo a los presupuestos causales, fácticos y jurídicos que justificaron y fundamentaron el nombramiento y la consiguiente relación. Cesar a un funcionario interino porque no se ha presentado al proceso selectivo en el que se incluye su plaza es una circunstancia completamente ajena a la existencia de vacante y a la urgencia y necesidad de su desempeño. Más aún, cesado el funcionario interino por esa causa, la vacante permanecería, así como la urgencia y necesidad de su desempeño por cuanto el cese no deriva de una valoración administrativa sobre la desaparición de dichos presupuestos sino del acaecimiento de un hecho (no presentarse a un proceso selectivo). Y lo mismo ocurre, en realidad, si se le cesa por no superar el proceso selectivo en el que se incluía su plaza para estabilizar la plantilla, pues una cosa es el resultado subjetivo del funcionario interino en el proceso de estabilización y otra muy diferente el nombramiento y ocupación del puesto desempeñado por el funcionario interino, que serían los que determinarían el cese, y no el mero resultado negativo en el proceso selectivo. Obviamente los procesos de estabilización o consolidación se encaminan a la cobertura de los puestos por funcionarios de carrera, cesando consecuentemente a los funcionarios interinos. Pero este cese se producirá por la incorporación de funcionarios de carrera de nuevo ingreso (que por la configuración de tales procesos normalmente podrán ser los propios funcionarios interinos que consolidan así su relación funcionarial), no por circunstancias subjetivas del funcionario interino, como sería su no participación en el proceso o su fracaso en el mismo.

\subsection{Control del cese por desaparición de «urgencia y necesidad»}

Y aunque la relación funcionarial interina gane en estabilidad respecto a las causas, permanece la discrecionalidad de la Administración respecto a sus presupuestos a la hora de considerar que ya no concurren las razones de «urgencia» y «necesidad» que permitieron en su día el nombramiento, si bien el control judicial se intensifica, pues se trata de conceptos jurídicos indeterminados cuya existencia o inexistencia

15 STS 26 diciembre 1984.

16 STSJ Islas Baleares, 25 mayo 2001 (Rec. 69/2000), donde concurría la circunstancia de que el funcionario interino -Ingeniero de Caminos- realizaba, gracias a su titulación, otra serie de funciones «impropias» del puesto pero acordes con su capacitación técnica. En cualquier caso, la funcionaria de carrera nombrada -Licenciada en Derecho- estaba perfectamente habilitada para la realización de las funciones propias del puesto (Cuerpo de Superior de la Administración). No se tienen, pues, en cuenta las «funciones que realizaba el interino» sino las "funciones propias del puesto ocupado».

17 Supuesto analizado por las SSTSJ Asturias, de 15 noviembre 1999 (Rec. 3255/1997) y 9 febrero 2000 (Rec. 3660/1997), que se limita a considerar válido el cese decretado por la Administración por no superación del proceso selectivo de consolidación al que se había presentado el funcionario interino, tal y como establecían las bases del proceso selectivo en aplicación de la Ley a cuyo amparo se convocó: «La conformidad a derecho del indicado cese viene determinada no sólo en las bases de la convocatoria a la que concurso sin impugnarlas, sino también y de modo especial, por la finalidad perseguida en la indicada convocatoria, posibilitar el acceso a la función pública del personal interino en cumplimiento de lo prevenido en la Disposición Transitoria Tercera de la Ley 3/1985 de 26 de diciembre, de Ordenación de la Función Pública de la Administración del Principado de Asturias, recogiéndose, tanto en las Bases de la indicada Convocatoria, como en la mencionada Disposición Transitoria que, quienes no superen las pruebas o no se presenten a las mismas cesarán automáticamente en su relación de empleo con la Administración del Principado de Asturias, en consecuencia, ni las Bases de la Convocatoria vulneran el artículo 57.2 de la mencionada Ley que regula el cese de los funcionarios interinos al venir a cumplimentar su Disposición Transitoria Tercera referida al acceso a la condición de funcionario del personal interino y contratado al servicio de la Administración del Principado de Asturias en la fecha de su entrada en vigor». Por tanto, mera validez formal del cese en aplicación de las bases y de la Ley, pero sin cuestionar ésta. 
sobrevenida puede ser controlada por los Tribunales ${ }^{18}$ pero que, de haber desaparecido, determinan el cese pues la Administración no sólo no tiene el deber de mantener a un funcionario si ya no existen las razones de urgencia y necesidad que justificaron en su momento el nombramiento sino que incluso pesa sobre ella la obligación de extinguir la relación interina ${ }^{19}$.

Particularmente relevante es la desaparición sobrevenida de la «necesidad», cuya concreción puede realizarse en su dimensión objetiva -amortización del puesto ${ }^{20}$ - o en la acepción subjetiva de conveniencia de prestación de las funciones, en cuyo caso será necesario controlar que la Administración no incurra en desviación de poder al invocar la desaparición de la necesidad de la prestación de las funciones cuando posteriormente en el mismo puesto nombra otro funcionario, sea interino, sea de carrera a título temporal ${ }^{21}$.

El polémico debate suscitado por los «ceses de verano» de los funcionarios interinos en la docencia no universitaria evidencia la relevancia de la «necesidad» como presupuesto de constitución y mantenimiento de la relacional funcionarial interina. No obstante, esta perspectiva tradicional de la necesidad docente subyacente a la relación funcionarial interina se ha visto afectada por la argumentación relativa a la discriminación de la que los funcionarios interinos serían objeto respecto a los funcionarios de carrera, cuya relación permanece también en los meses de verano, pese a no haber actividad docente. De esta manera, en el análisis se han mezclado elementos estructurales de la relación (presupuesto de necesidad) con el contenido sustantivo de la misma (derechos de los funcionarios interinos), confundiendo en última instancia las argumentaciones. Este debate ha exigido no sólo la precisión de conceptos organizativos como «curso académico» o «período lectivo» sino que también ha propiciado la intervención de sucesivas instancias judiciales, incluida la europea, para aclarar la aproximación al problema desde la citada discriminación o desde los presupuestos y fundamentos de la relación interina.

Tradicionalmente el cese de los funcionarios docentes no universitarios al finalizar el curso se fundamentaba en la terminación de la necesidad que constituye el presupuesto de la relación interina. De ahí también que los nombramientos pudieran fijar el momento del cese por cuanto podían en ese momento inicial prever objetivamente la desaparición de la necesidad de desempeño de las funciones. Al abordarse la cuestión, en la práctica, desde la perspectiva estructural de la necesidad como presupuesto de la relación, resulta indiferente que el nombramiento lo sea en vacante o en razón de funciones o tareas derivadas de la programación docente (reconducible imprecisamente a la modalidad del «funcionario de programa»).

Como necesidad docente objetivada por el servicio público docente vemos un buen ejemplo en la Sentencia del Tribunal Suprior de Justicia de Madrid, 24 noviembre 199822:

«el ahora demandante fue nombrado funcionario interino del Cuerpo de Profesores de Enseñanza Secundaria por un período concreto y previamente determinado (del 4 de octubre de 1995 al 14 de septiembre de 1996), espacio temporal que coincide con la duración del curso académico 1995-1996. Este hecho, no cuestionado en su momento por el interesado, hace inconsistente la alegación de que su cese sólo podía tener lugar por la cobertura de la plaza en propiedad o por amortización de la misma, pues es incuestionable que su nombramiento tenía un período de vigencia (la duración del aludido curso académico), lo que además es coherente con los servicios docentes encomendados y con los mecanismos de cobertura de este tipo de plazas, que se verifican, cuando se trata de funcionarios que no son de carrera, por cursos académicos y teniendo en cuenta la puntuación obtenida en las pruebas selectivas de acceso al correspondiente Cuerpo docente. La tesis expuesta no se ve afectada por la circunstancia de

18 STSJ Andalucía, 3 enero 2001 (Rec. 173/2000): «el cese de los citados funcionarios interinos puede producirse cuando, a juicio de la Administración, cesen las razones de urgencia. Pero dicha apreciación de la Administración Pública está sujeta al control jurisdiccional pues el concepto de urgencia, como concepto jurídico indeterminado, no admite sino una solución única, o existe urgencia o no, y no cabe, por tanto, que arbitrariamente la Administración decida, sin criterio alguno o haciendo alusión a motivos inexistentes, cuando han cesado las causas de urgencia. En este sentido, en los presentes Autos la urgencia aludida ha sido interpretada de dos formas distintas por la Administración demandada. En primer lugar, en el nombramiento, en que se condicionaba dicha urgencia a que se incluyera la plaza en el Presupuesto de 1999 o éste no fuera objeto de aprobación. En segundo lugar, en el momento de acordar el cese en que la urgencia aludida se condicionó a que se reincorporara a su plaza original la funcionaria nombrada en otra plaza. Pues bien, de la documentación y prueba que consta en autos, como ya se ha expuesto, no se desprende que en el momento de cese de la actora en el proceso de instancia concurrieran ni una ni otra, por lo que procede la desestimación del Recurso de Apelación interpuesto».

19 STSJ Castilla y León, 8 noviembre 2002 (Rec. 431/2001).

20 La decisión de amortización del puesto implica un juicio de desaparición sobrevenida de la necesidad del ocuparlo: STSJ de Murcia, 22 julio 2016 (38/2016).

21 Por ejemplo, en comisión de servicios: STSJ Galicia, 20 abril 2011 (376/2010) y STSJ Aragón, 4 noviembre 2015 (33/2014).

22 Rec. 1625/1996. 
que la profesora a la que inicialmente sustituyó el actor renunciase a su condición de funcionaria de carrera en diciembre de 1995, ya que ese dato no confiere al interino el derecho a continuar en el desempeño de sus funciones más allá del tiempo previsto ni, en su caso, después de que la Administración considere que ya no concurren las razones de necesidad que motivaron el nombramiento» ${ }^{23}$.

En la medida en que se consideraba que el devenir docente del curso académico determinaba que, finalizado el período lectivo en sentido estricto, desaparecía la necesidad de interinidad, lo fuera por vacante o por sustitución, no sólo los nombramientos individuales sino también las previsiones normativas e incluso presupuestarias (dotaciones en concepto de sustitución) fijaban sistemáticamente el 30 de junio como término objetivo de desaparición de la necesidad funcional que amparaba y justificaba el nombramiento inicial y la extensión temporal de la relación.

Sin embargo, este análisis de la cuestión se vio alterado por la introducción -vía Derecho europeo- de la perspectiva de igualdad de condiciones con funcionarios de carrera. En efecto, se invocó la Directiva 1999/70 y su prohibición de discriminación entre trabajadores de duración determinada y de duración indeterminada, para cuestionar los ceses de verano, adulterando, en última instancia, la argumentación, pues se mezclaban los planos de análisis: el estructural de los presupuestos y causas de la relación con el sustantivo de los derechos de la misma.

Como exponente de esta línea argumental podemos citar la STSJ de Extremadura de 23 de diciembre de 201124: "Una vez procedido a la designación del funcionario en el puesto, el que lo desempeñase habría de quedar sometido a las mismas condiciones que el funcionario de carrera, que en el sistema ordinario de provisión, le fueran aplicable; que no es desde luego, el cese durante la época estival por falta de la actividad docente -que no excluya la actividad profesional en todo caso-. En definitiva, que no se duda de la finalidad de la actividad que se recurre en orden a la necesaria economía en la gestión administrativa, evitando el nombramiento de una plaza por no existir actividad docente durante los meses de verano y volver a efectuar el nombramiento para el siguiente curso; sin embargo, ese cese no se produce -ni se habría producido- de haberse tratado de un funcionario de carrera, por lo que estando sometido al mismo régimen el sustituto, debe excluirse esa posibilidad. Y no es objetable a lo razonado el hecho de que no hubiera actividad alguna en el centro porque cabe pensar que si los profesores del centro siguen prestando sus servicios -exclusión hecha del preceptivo periodo vacacional-, cabe concluir que también ese concreto puesto tendría asignadas actividades durante ese periodo».

Pero mayor trascendencia tuvo la STS de 11 de junio de 2018, donde el Tribunal Supremo, en esa línea de igualdad de derechos, interpretó que curso escolar y período lectivo no se identifican, pues las funciones docentes de los puestos cubiertos interinamente permanecerían durante los meses de julio y agosto, por lo que los célebres «ceses de verano» con fecha 30 de junio no estarían justificados ${ }^{25}$.

Sin embargo, la posterior Sentencia del Tribunal de Justicia de la Unión Europea Viejobueno Ibáñez, 21 de noviembre de $2018^{26}$ recondujo el análisis precisamente a los elementos estructurales de la relación temporal, lo cual no dejó de ser sorprendente para aquellos que precisamente forzaron la argumentación sustantiva de igualdad de derechos con la intención de obviar los presupuestos organizativos de la relación funcionarial interina. El Tribunal de Justicia nunca ha demonizado las relaciones temporales: sólo lo ha hecho con su abuso. Y si encuentra efectivamente fundamentadas las necesidades temporales no permite que la perspectiva de prohibición de discriminación desvirtúe aquellas.

23 «En efecto, tanto la Orden de 28 febrero 1986 (RCL 19861876) como la jurisprudencia de la Sala Tercera del Tribunal Supremo (Sentencias de 12 mayo 1986 [RJ 1986/2912 ], 14 abril 1997 [RJ 1997/3313 ] y 12 enero 1998 [RJ 19981819 ], entre otras), proclaman que la relación funcionarial del interino es esencialmente temporal y puede finalizar por libre remoción de la Administración en tanto desaparezcan a juicio de la misma las razones de necesidad o urgencia que motivaron el nombramiento, pues dichos funcionarios no gozan del derecho de inamovilidad. Así, es patente que la norma somete la continuidad del interino al criterio administrativo sobre el mantenimiento de las condiciones que motivaron su nombramiento, de tal manera que, al corresponder a la Administración la determinación de las necesidades personales que precisa para el cumplimiento de sus fines, ese juicio subjetivo -consecuencia de su facultad de auto organización- debe ser respetado salvo que se acredite que ha hecho uso de tal potestad con, finalidades distintas de las previstas en el Ordenamiento jurídico. En el presente caso, según se ha visto, el nombramiento del recurrente durante un curso académico tenía por finalidad garantizar el correcto desarrollo de la actividad docente, de manera que debe considerarse ajustado a Derecho el cese del interesado al término del curso 1995-1996, momento en el que dejaron, de existir las razones de necesidad que justificaron la cobertura interina de la plaza; motivos que provocan la íntegra desestimación del recurso».

24 Rec. 217/2011.

25 STS de 11 de junio de 2018

26 Asunto C-245/2017. 
Así, en esta Sentencia, el Tribunal de Justicia constata que, siendo en principio comparables las situaciones de los funcionarios docentes interinos y de carrera atendiendo a sus funciones, en realidad la diferencia de trato invocada -el cese al finalizar el período lectivo- «deriva únicamente del hecho de que la relación de servicio de los interesados finalizó en una fecha determinada, mientras que la de los docentes que eran funcionarios de carrera se mantuvo después de dicha fecha», pero «tal circunstancia constituye la característica fundamental que distingue una relación de servicio de duración determinada de una relación de servicio por tiempo indefinido. En efecto, el hecho de que, en la fecha de finalización de las clases, no se extinga la relación de servicio de los docentes que son funcionarios de carrera o de que esta relación no se suspenda es inherente a la propia naturaleza de la relación de servicio de estos empleados. En efecto, estos están llamados a ocupar una plaza permanente precisamente porque su relación de servicio es por tiempo indefinido. En cuanto a las relaciones de servicio de duración determinada, como las de los interesados, se caracterizan en cambio, como se desprende de la cláusula 3, apartado 1, del Acuerdo Marco, por el hecho de que el empleador y el empleado acuerdan, cuando se inicia la relación, que esta se extinguirá cuando se produzca una circunstancia fijada de manera objetiva, como la finalización de una tarea determinada, el advenimiento de un acontecimiento concreto o, incluso, una fecha concreta».

Concluyendo, en este primer punto, que «el Acuerdo Marco reconoce en principio la legitimidad de recurrir a relaciones de servicio por tiempo indefinido y también de hacerlo a relaciones de servicio de duración determinada, $y$, en la medida en que no establece en qué condiciones se puede hacer uso de unas y de otras, no cabe sancionar, sobre la base de dicho Acuerdo, una diferencia de trato como la que es objeto del litigio principal, consistente en el mero hecho de que una relación de servicio de duración determinada se extingue en una fecha dada, mientras que una relación de servicio por tiempo indefinido no se extingue en esa fecha».

Rebate también la argumentación de la Comisión según la cual «la mera naturaleza temporal de la relación de servicio no puede constituir una "razón objetiva" que pueda justificar una diferencia de trato en el sentido de la cláusula 4, apartado 1, del Acuerdo Marco». Pero según el Tribunal de Justicia, esta diferencia de trato «es inherente a la coexistencia de relaciones de servicio por tiempo indefinido y de duración determinada y no puede estar cubierta por la prohibición recogida en dicha cláusula, so pena de eliminar cualquier diferencia entre estas dos categorías de relaciones de servicio.». Esto es, la prohibición de discriminación no puede abocar a una confusión de las relaciones temporales y permanentes pues sus presupuestos son cualitativamente diferentes.

Al amparo de esta Sentencia del Tribunal de Justicia de la Unión Europea, el Tribunal Supremo revisó su doctrina de 2018, sentando, en su Sentencia de 9 de julio de $2019^{27}$, «que el cese de los funcionarios docentes interinos de los Cuerpos Docentes no universitarios al final del período lectivo del curso escolar, basado sólo en la causa de que en los dos meses restantes de éste (julio y agosto) desaparece la necesidad y urgencia que motivó su nombramiento, no comporta un trato desigual no justificado con respecto a los funcionarios docentes fijos o de carrera».

Esta doctrina se fundamentaba en un desarrollo argumental relativamente sucinto, que en última instancia descansaba en la jurisprudencia del Tribunal de Justicia de la Unión Europea (en particular, Viejobueno). Dicha argumentación señalaba, si bien los funcionarios interinos ejercían las mismas funciones que los docentes que eran funcionarios de carrera y, por tanto, resultaban funcionarios comparables, existía una razón objetiva que amparaba que la finalización del período lectivo recibiera un tratamiento diferenciado entre los docentes en función de que sean funcionarios interinos o funcionarios de carrera. Esa diferencia de trato derivaría únicamente del hecho de que la relación de servicio de los funcionarios interinos finaliza en una fecha determinada, mientras que la de los docentes que eran funcionarios de carrera se mantiene después de dicha fecha.

Esta fundamentación vendría enriquecida posteriormente por la STS de 16 de julio de $2020^{28}$ que, además de abordar una perspectiva complementaria de igualdad de atribución de funciones, respecto a la cuestión estricta del cese en los meses de verano por desaparición de la necesidad de la relación añadió que la comparabilidad de la situación de los funcionarios interinos -que ejercen las mismas funciones que los docentes que son funcionarios de carrera- no impide que, en atención a circunstancias objetivas -como concretamente la fijación de una fecha predeterminada objetivamente como determinante del cese-, éste

27 Rec. cas. núm. 1930/2017.

28 Rec. 793/2018. En idéntico sentido, SSTS de 12 de noviembre de 2020 (Rec. 6469/2018) y de 3 de diciembre de 2020 (Rec. 1809/2019). 
sea acordado por la Administración por razones objetivas, a diferencia de los trabajadores fijos comparables, los funcionarios de carrera. $Y$ es que el cese de los funcionarios interinos responde a la finalización de la causa que motivó cada uno de sus nombramientos como funcionaria interina, siendo tal causa objetiva la finalización del respectivo período lectivo del curso escolar, que se produjo el 30 de junio, y sobre la base de una configuración previa de la relación jurídica de servicio de tiempo determinado, que tuvo en cuenta de manera predeterminada el efecto extintivo de la finalización del periodo lectivo.

Para el Tribunal Supremo,

«La elección de una relación de servicio de duración determinada deriva únicamente de una razón objetiva, la introducción de nuevas medidas organizativas en la prestación del servicio público de educación, en particular en la actividad genuinamente docente, encaminadas además a la consecución de un objetivo de interés público igualmente relevante, cómo es la reducción del déficit público, y establecidas en una norma de rango legal, como son las disposiciones presupuestarias con rango de ley a que hace referencia la Administración recurrente. Esta elección de una relación de servicio determinada, justifica un trato diferenciado entre los docentes, en función de que sean funcionarios interinos o funcionarios de carrera, dado que la relación deservicio de la interesada finalizó en unas fechas determinadas, como la de los demás interinos docentes, esto es, en aquellas en que se produjeron la finalización de las necesidades lectivas del curso escolar y, por ende, la extinción de las causas que determinaron su nombramiento, lo que además estaba previsto en sus nombramiento de forma objetiva y predeterminada, mientras que la de los docentes que eran funcionarios de carrera se mantuvo después de dicha fecha, correspondiendo a los mismos realizar todas cuantas labores administrativas y organizativas son propias del periodo no lectivo del curso escolar, y están establecidas en las ordenes reguladoras de la programación de los sucesivos cursos escolares. Por tanto, la proscripción de discriminación en el tratamiento, a tenor del estatuto jurídico de funcionarios de carrera y funcionarios interinos, no ha sido vulnerada. Además, las razones de índole organizativa consideradas por la Administración para la determinación de manera predeterminada de la fecha de finalización de la relación de servicio (finalización del periodo lectivo del curso escolar), en cuanto fundadas en un objetivo de naturaleza pública igualmente relevante, no pueden tacharse por si mismas de medidas de trato discriminatorio para los funcionarios interinos».

\section{2. «Estabilidad subjetiva»: la desvinculación del funcionario interino del puesto de trabajo}

La estabilidad de los funcionarios interinos también se alcanza relativizando uno de los elementos esenciales de la relación funcionarial interina, cual es la vinculación de ésta al puesto de trabajo, caracterizándola así por su naturaleza objetiva. Esto quiere decir que dicha relación existe y subsiste por referencia a un puesto o a una función, mientras que en el caso de los funcionarios permanentes de carrera su relación jurídica con la Administración no precisa del presupuesto del elemento objetivo «puesto» o «función».

De esta manera, la relación jurídica de los funcionarios permanentes de carrera es subjetiva, pues atiende al sujeto de dicha relación, conformando una condición personal y, en definitiva, un estatuto jurídico subjetivo desvinculado del puesto en cuanto que elemento objetivo. Sin embargo, el puesto o función -elementos objetivos de la organización administrativa- constituye un presupuesto esencial de la relación funcionarial interina, razón por la cual la Ley de Funcionarios Civiles de 1964 los clasificaba significativamente como «funcionarios de empleo». Por ello, la desaparición del puesto vía amortización constituye causa de cese del funcionario interino, mientras que en el caso de los funcionarios permanentes de carrera su relación jurídica pervive a pesar de dicha amortización, estando obligada la Administración, en tal caso, a adscribir provisionalmente al funcionario de carrera a otro puesto, no pudiendo, en cambio, acordar la pérdida de la condición de funcionario.

La inextricable relación del funcionario interino con su puesto de trabajo o con las funciones que desempeña lleva a cuestionar que sea posible interrumpir el servicio que presta al amparo de derechos que, no obstante, supondrían el mantenimiento de la relación y excluirían la posibilidad de extinción de la relación. No se trata tanto de técnicas por las que formalmente la Administración desvincula al funcionario interino del puesto (remoción o sanción disciplinaria) sino del ejercicio por éste de derechos -incluidas las situaciones administrativas que articulan derechos- que producen la suspensión funcional de la relación. La aparente contradicción de este efecto suspensivo de la prestación de funciones con la esencia de la interinidad ex- 
plica que, sustantivamente, haya sido considerado un aspecto que no sería «adecuado a la naturaleza de su condición» funcionarial interina y, formalmente, causa del cese de la relación. En última instancia, la suspensión de la relación al amparo de diferentes títulos implica la reserva del puesto, reserva que en principio es un derecho específico de quienes lo ostentan en propiedad ${ }^{29}$ y para quienes su relación jurídica con la Administración crea un estatuto subjetivo desvinculado del puesto. Más aún si la suspensión del servicio activo del funcionario interino trae causa de una situación administrativa que a fortiori ni siquiera conlleve la reserva del puesto.

Éste último sería el caso de la excedencia voluntaria por interés particular, que tradicionalmente tanto la doctrina ${ }^{30}$ como la jurisprudencia ${ }^{31}$ negaban a los funcionarios interinos. Por ello resulta de gran interés la Sentencia del Tribunal Superior de Justicia de la Comunidad Valenciana, de 16 de septiembre de 2020 ${ }^{32}$, que reconoce a un funcionario que llevaba prestando siete años de servicio el derecho a la excedencia voluntaria por interés particular. La Administración rechazó su concesión -entre otros argumentos- porque la razón de ser del funcionario interino es la prestación de las funciones de un puesto, además de que, al estar vinculado el nombramiento de un funcionario interino a un determinado puesto y no conllevar la excedencia voluntaria reserva del mismo, sería imposible su reingreso.

Sin embargo, la duración prolongada de la relación interina lleva a la Sentencia a señalar que, «siendo cierto que la excedencia voluntaria por interés particular supone la cesación temporal de la prestación de servicios, sin extinción de la relación jurídica estatutaria, que mantiene el funcionario de carrera con la administración pública en la que se integra, y que este efecto de no suprimir la relación jurídica estatutaria tan sólo tiene sentido cuando ésta tiene carácter permanente, pero no cuando el vínculo tiene naturaleza temporal», la razón de ser de esta última diferenciación «se desvanece» cuando la «relación temporal» dura mas de siete años. Por tanto, la duración temporal excesiva ampararía la suspensión de la relación.

$Y$ en lo que respecta al argumento de la Administración de que, al estar vinculado el nombramiento interino a un puesto de trabajo y no conllevar la excedencia voluntaria por interés particular reserva de puesto de trabajo, seria imposible su reingreso, la Sentencia señala que ni siquiera el funcionario de carrera que pasa a la situación de excedencia voluntaria por interés particular tiene reserva de puesto de trabajo, pudiéndosele denegar el reingreso si no hay puesto vacante de su cuerpo o escala, por lo que, de igual forma -razona la Sala- el funcionario interino podría «solicitar su reingreso a través de la adscripción provisional, sujeto siempre a las necesidades de la administración». Este es, sin duda, el argumento más forzado de la sentencia, pues implícitamente está dotando a la interinidad funcionarial de una condición de estatus subjetivo de la que carece, desligándola del puesto de trabajo que le confiere precisamente ese carácter objetivo a la relación.

En efecto, el hecho de que la excedencia voluntaria por interés particular no implique reserva de puesto produce una desvinculación formal y voluntaria del funcionario interino del puesto en el que fue nombrado. No se trata, por tanto, de una desaparición de la necesidad subyacente a la relación interina por decisión organizativa de la Administración (v. gr. amortización del puesto o remoción del funcionario interino) sino de la voluntad del funcionario interino no ya de suspender su desempeño del puesto o función sino de finalizarlo, manteniendo en cambio la relación funcionarial. Y es que esa finalización deriva de la imposibilidad de volver al puesto al terminar la excedencia, por la ya mencionada carencia de reserva de puesto en el régimen jurídico de dicha situación administrativa.

Escindido el funcionario interino de su puesto, su relación jurídica perviviría como estatus subjetivo o como condición personal. Esta era precisamente una de las características diferenciadoras de los funcionarios interinos y de los funcionarios de carrera, pues dicho estatus subjetivo se predicaba como exclusivo de estos últimos. En principio y a la vista de la reconceptualización del funcionario interino por mor de la evolución que está propiciando en particular el Derecho europeo ${ }^{33}$, sería posible manejar la hipótesis de que también los funcionarios interinos gozaran de un estatus subjetivo y no objetivo por la pervivencia de la relación funcionarial interina desligada del puesto o función. Pero para ello habría que afirmar la aplicabilidad de las técnicas que posibilitan la subsistencia de la relación funcionarial desvinculada del puesto, encauzando

29 STSJ Andalucía, 13 febrero 2020 (Rec. 2241/2019), que niega la posibilidad de que los funcionarios interinos puedan ser nombrados en puestos o cargos directivos intermedios, nombramiento que implicaría suspensión de la relación funcionarial interina y reserva del puesto que desempeña a título temporal.

30 Véanse los sólidos argumentos de SÁNCHEZ MORÓN, M., Régimen jurídico ... op. cit., pág. 94 y ss.

31 Por ejemplo, STSJ Galicia, 21 enero 1998 (Rec. 2002/1994).

32 Rec. num. 353/2017.

33 Vid. CANTERO MARTÍNEZ, J.: "El funcionario interino en la jurisprudencia: sobre la necesidad de repensar la figura" en Revista Vasca de Gestión de Personas y Organizaciones Públicas, núm. 12, enero-junio 2017, págs 8-29. 
la nueva asignación de otro puesto para hacer posible el reingreso al servicio activo de los funcionarios. Así lo hace la Sentencia que comentamos, considerando factible la adscripción temporal del funcionario interino a un nuevo puesto, si bien el régimen de dicha adscripción no parece adecuado, pues exigiría del funcionario interino la participación en las convocatorias de provisión del puesto, cuando tal participación le estaría vedada. E incluso desde la perspectiva del propio régimen del funcionario interino, la adscripción implica un nuevo nombramiento sin seguir los procedimientos de selección de los funcionarios interinos, conculcando los derechos del resto de candidatos de tales procedimientos.

Todo ello permitiría concluir que, aun admitiendo derechos laborales que amparan la suspensión del desempeño activo de las funciones de puesto (caso obvio de vacaciones e incapacidades temporales), resulta complejo admitir la suspensión del servicio activo vía situaciones administrativas que implican reserva de puesto ${ }^{34}$ y casi imposible cuando no existe tal reserva, lo que no haría sino confirmar la naturaleza objetiva de la relación funcionarial interina por su vinculación a un determinado puesto.

Pero además de la desvinculación voluntaria del puesto a través de situaciones administrativas sin reserva del mismo, aquella puede ser el resultado unilateral de la actuación de la Administración. Tal es el caso de la remoción por alteración del contenido del puesto o por falta de capacidad para su desempeño ${ }^{35}$, que mientras que para los funcionarios de carrera limita sus efectos a la pérdida del puesto pero perviviendo la relación funcionarial, en el supuesto de los funcionarios interinos la remoción determinaría la extinción de dicha relación. Tal singularidad del régimen funcionarial interino ha sido cuestionada incluso como discriminatoria respecto a los funcionarios de carrera, valoración que tradicionalmente era rechazada ${ }^{36}$ pero que últimamente, en virtud del Derecho europeo, ha sido admitida.

En efecto, el Tribunal Supremo ha terminado por cuestionar que la remoción en el puesto de trabajo del funcionario interino pueda constituir una causa de cese en su relación funcionarial. La Sentencia de instancia del Tribunal Superior de Justicia de Andalucía, de 9 de mayo de $2016^{37}$ declaró la nulidad de una norma ${ }^{38}$ que establecía como causa de cese del personal interino en el puesto de trabajo que viniere desempeñando y la exclusión de la bolsa de trabajo vigente la manifiesta falta de capacidad así como el rendimiento insuficiente, cuando no comportara responsabilidad disciplinaria. Y lo hizo por considerar que en realidad se trataba de una sanción encubierta y no se respetaba el art. 25.1 de la Constitución, que impone el principio de legalidad de infracciones y sanciones. Sin embargo, el Tribunal Supremo, en su Sentencia de 21 de noviembre de $2017^{39}$, parte de la equiparación de regímenes entre los funcionarios de carrera e interinos de la Administración de Justicia y señala que «la medida de cese no está prevista para los funcionarios titulares en los supuestos en que se aprecie la manifiesta falta de capacidad o el rendimiento insuficiente en el desempeño de su puesto de trabajo».

A continuación, descarta el razonamiento según el cual la carencia de estabilidad en el empleo sería una razón que justificaría la diferencia objetiva en el trato a los funcionarios interinos, al permitir acordar el cese por razones que no tenían por qué estar previstas para los funcionarios de carrera. Que el funcionario interino no tenga derecho a la fijeza en el puesto de trabajo no significa que no tenga derecho a la estabilidad en el empleo, dentro de las peculiaridades de su régimen, y por ello, su cese solo podrá acordarse como de una de las causas previstas en la Ley o como consecuencia de la imposición de la sanción de separación del servicio, cuando incurra en infracción disciplinaria muy grave. En todo caso, la normativa que establezca las causas de cese habrá de respetar los principios legales que regulan la relación de servicio del funcionario

34 Aunque la jurisprudencia, al amparo del Tribunal de Justicia de la Unión Europea [Vega González, 20 diciembre 2017 (C158/16)], admite el derecho a los servicios especiales del funcionario interino: STS de 14 de octubre de 2020 (Rec. 6333/2018).

35 Sobre la remoción en cuanto técnica de cese de funcionarios de carrera en puestos obtenidos por concurso, vid. PARADA, R. y FUENTETAJA, J., Derecho de la Función Pública, 2. ${ }^{a}$ ed., Civitas, 2019, págs. 349-351.

36 STS de 29 de octubre de 2010 (Rec. 4575/2007): «las notas diferenciales que acaban de exponerse son las que impiden compartir la tesis mantenida por el recurso sobre esas cuestiones sustantivas de las que se viene hablando, y así debe ser por lo siguiente: (a) el funcionario interino ha de reunir los requisitos de capacidad que en cada momento resulten necesarios para el desempeño de los puestos cuya atención resulta conveniente en razón de esas circunstancias de urgencia y necesidad y, además, sus derechos duran, como ya se ha dicho, en tanto subsisten esas circunstancias que determinan su nombramiento; y (b) por el contrario, el carácter permanente que caracteriza al funcionario de carrera hace que los cambios que se introduzcan en su estatuto impongan como necesarias unas modulaciones o excepciones que, para aquellos que ingresaron con unos requisitos diferentes a los nuevamente exigidos, hagan posible esa continuidad o permanencia que por imperativo legal caracteriza a su vínculo de servicios».

37 Rec. 284/2015.

38 Se trataba de la Orden de 2 de marzo de 2015, sobre selección y nombramiento de personal funcionario interino de los Cuerpos al servicio de la Administración de Justicia en el ámbito de la Comunidad Autónoma de Andalucía.

39 Rec. núm. 2996/2016. 
interino, principios que el Tribunal Supremo considera «presididos por el mandato de no discriminación, por lo que, en la expresión de la cláusula 4 del anexo de la Directiva 199/70, no se les podrán imponer ninguna condición "[...] menos favorable que a los trabajadores fijos comparables por el mero hecho de tener un contrato de duración determinada, a menos que se justifique un trato diferente por razones objetivas"».

Y discriminación es lo que el Tribunal Supremo aprecia cuando a los funcionarios de carrera cesados por incompetencia se les adscribe a otro puesto, mientras que a los funcionarios interinos que adolecen del mismo defecto se les cesa en su condición funcionarial interina. Más aún, refuerza su argumentación al amparo de la Directiva 1999/70 para afirmar no sólo la estabilidad de los funcionarios interinos en este tipo de situaciones sino también su estatus jurídico:

«No cabe negar que en determinadas situaciones o respecto a determinados puestos de trabajo, se pueda constatar que el tiempo que el funcionario interino necesita para adaptarse a los requerimientos específicos, unido a la temporalidad intrínseca a la situación de vacante, requerirá de alguna medida para garantizar la adecuada prestación del servicio público. Pero tales situaciones pueden solucionarse bien con el necesario apoyo al funcionario interino, para adquirir las destrezas y capacidades necesarias mediante las actuaciones de formación específicas, bien, en última instancia, con la reubicación en otro puesto de trabajo demandado de cobertura por funcionario interino, satisfaciendo de esta forma el mandato de trato no menos favorable que el personal fijo equiparable (funcionario de carrera) que impone la Directiva 1999/70. Las obligaciones de promoción de las oportunidades de trabajo constituyen parte de las obligaciones que debe respetar la Administración como empleadora de personal interino, y así lo establece la cláusula 6 del anexo de la Directiva 199/70 sobre obligaciones del empleador sobre información y oportunidades de empleo, cuando prevé que "[...] (cláusula 6) [...] 2. En la medida de lo posible, los empresarios deberán facilitar el acceso de los trabajadores con contrato de duración determinada a las oportunidades de formación adecuadas para mejorar su cualificación profesional, el desarrollo de su carrera laboral y su movilidad profesional". La medida de cese prevista en la orden impugnada desconoce por completo esta obligación de promover y adoptar medidas de formación como medio para superar el desajuste entre las habilidades del funcionario interino y los requerimientos del puesto de trabajo, y además cercena injustificadamente sus oportunidades de carrera laboral y movilidad profesional, al excluirle de la bolsa de empleo y, por tanto de optar a otro nombramiento».

Al final el Tribunal Supremo concluye que la consecuencia del cese en la relación funcionarial interina ante la falta de idoneidad o capacitación para el desempeño del puesto o de las funciones «resulta incoherente y por ello injustificado, por la propia configuración del sistema de acceso a la bolsa de empleo -que atiende y garantiza el respeto a los principios de mérito y capacidad-». Diferente cuestión es la consecuencia consistente en la exclusión de la bolsa de trabajo, la cual, en sí misma, es ajena a la estricta relación jurídica funcionarial interina. Si ésta sí puede verse afectada de alguna manera por la inidoneidad revelada a posteriori para el ejercicio del puesto, dicha inidoneidad respecto a un puesto no tiene por qué afectar a la presencia de la persona en cuestión en la bolsa de trabajo ${ }^{40}$. Por ello se entiende que el Tribunal Supremo considere que la exclusión de la bolsa por ser cesado en el puesto resulta una medida desproporcionada - «pues impide que el funcionario interino pueda ser nombrado para otro puesto de trabajo en que no se observara aquel desajuste» entre habilidades del funcionario interino y los requerimientos del puesto de trabajo- y además debe calificarse como «aflictiva y objetivamente indistinguible de la sanción de cese», por lo que cabría considerarla contraria al art. 25.1 de la Constitución, por no venir tipificada legalmente como tal infracción.

\section{3. «Estabilidad discontinua»: las bolsas de trabajo}

Otra técnica de estabilización de las interinidades deriva indirectamente de las listas o bolsas de interinos. Estas listas o bolsas se confeccionan mediante procesos selectivos con una vigencia temporal determinada y, a partir de ella, se producen los concretos nombramientos al concurrir los presupuestos y circuns-

40 Esa relativización de las consecuencias y alcance de la inidoneidad se encuentra también en STSJ Aragón, 16 mayo 2005 (Rec. 65/2004). 
tancias que los amparan. Se produce así la equívoca consecuencia de permanencia vía listas o bolsas que induce a pensar en la interinidad funcionarial como una "condición» o como un estatus ${ }^{41}$. De esta forma, el funcionario interino puede cesar en la relación funcionarial pero permanece en la bolsa de interinos, lo que, según los criterios de gestión de las mismas, le garantiza nuevos nombramientos (estabilidad discontinua). Esta vigencia de las bolsas o listas propicia una sucesión -aun interrumpida- de relaciones funcionariales interinas que, en determinadas circunstancias o ámbitos sectoriales (por ejemplo, educación) pueden permitir considerar que no se ha producido «una ruptura de la unidad esencial del vínculo existente entre las partes $»^{42}$. De ahí que se pueda hablar más bien de estabilidad o continuidad no tanto de relaciones jurídicas como de situaciones interinas.

Obviamente, la continuidad de nombramientos vía bolsas o listas no es lo más acorde con las características de la figura del funcionario interino, pues resultan «incompatibles por definición con marcos de estabilidad y permanencia en puestos de trabajo, propios de los funcionarios de carrera y, en menor medida también del personal laboral fijo, que sólo después de superados los correspondientes procesos de selección adquirirán el status y vinculación permanente con las administraciones a las que sirvan» ${ }^{43}$. Pero lo cierto es que constituye un sistema eficiente y eficaz para organizar los nombramientos y responder así a la urgencia que presuponen. El problema es cuando la regulación, duración y gestión de las bolsas propicia esos «marcos de estabilidad» que generan expectativas en los afectados de permanencia en la situación laboral. El uso y abuso de las listas y bolsas de interinos no es un fenómeno ajeno al del uso y abuso de las interinidades, del que no están exentos los propios afectados, en particular a través de la negociación colectiva protagonizada por las organizaciones sindicales, pues la regulación no ya legislativa sino incluso reglamentaria de estas bolsas es prácticamente inexistente o insuficiente.

\section{4. «Estabilidad tuitiva»: protección de la relación interina como criterio interpretativo}

La protección de la relación funcionarial interina se erige en criterio interpretativo a la hora de aplicar la normativa cuando pudiera determinar el cese, ponderando o primando su permanencia frente a otros bienes o derechos.

Así lo observamos en los casos de cese de funcionarios interinos ante nombramientos de funcionarios de carrera a título temporal, mediante comisiones de servicio ${ }^{44} \mathrm{o}$ adscripción provisional ${ }^{45}$, donde se discute si la ausencia de carácter definitivo de la ocupación de la vacante por el funcionario de carrera resulta adecuada a efectos de extinguir la relación funcionarial interina.

Esta protección de la relación interina la encontramos con mayor alcance en los supuestos de conversión de la modalidad de la relación funcionarial interina para evitar el cese. En efecto, algunos Tribunales han recurrido a la conversión de la modalidad de interinidad para preservar la relación funcionarial, evitando así el cese por finalización de la causa que dio origen al nombramiento. Este supuesto se produce sobre todo en casos de funcionarios interinos de sustitución que, al perder el titular del puesto el derecho de reserva sobre el puesto (por ejemplo, por jubilación), abocarían en principio al cese de la relación funcionarial interina. Sin embargo, algunos Tribunales entienden que, en tales casos, aunque finaliza la causa de sustitución, existe otra causa -la vacante- que ampararía la conversión de la interinidad.

41 STS 16 julio 2020 (Rec. 793/2018).

42 STSJ La Rioja, 4 mayo 2020 (Rec. 92/2019), donde el Tribunal hace una exposición de los hechos que trasciende la descripción fáctica para introducir la valoración jurídica decisiva que se recoge en el texto principal: «Del examen del expediente administrativo resulta que doña Enriqueta es profesora interina de enseñanza secundaria desde su primer nombramiento el 15 de septiembre de 2001 hasta el nombramiento que finaliza el 31 de agosto de 2018, en diferentes Institutos de Educación Secundaria, con o sin solución de continuidad, dados los ceses con motivos de los períodos estivales, en algunas ocasiones. La solicitud presentada por la ahora apelada se fundamentó en que venía prestando servicios para la citada Consejería desde el curso académico 2001/2002, en virtud de sucesivos nombramientos como funcionario docente interino. Desde el 16 de septiembre de 2005, los nombramientos anuales han sido para la especialidad Física y Química y Matemáticas. Al finalizar un vínculo era automáticamente nombrada para el curso siguiente, produciéndose escasas y cortas interrupciones, coincidentes con las vacaciones anuales, que no pueden ser consideradas como una ruptura de la unidad esencial del vínculo existente entre las partes».

43 STSJ País Vasco, 29 noviembre 2002 (33/2001).

44 A favor del cese, por ejemplo, SSTSJ Andalucía, 27 junio 2002; Cataluña, 22 febrero 2012; Madrid, 25 abril 2014, que se acogen a la argumentación literal de que, siendo la comisión de servicios, una forma de provisión de puestos de trabajo, el nombramiento en tal calidad de un funcionario de carrera supone la ocupación de la vacante. En contra, SSTSJ Madrid, 30 diciembre 2009 y Cataluña, 26 septiembre 2005, que entienden que no concurre urgencia y necesidad para el nombramiento en comisión de servicios de un funcionario de carrera porque el desempeño del puesto por funcionario interino impide apreciar tales presupuestos.

45 STSJ Madrid, 19 febrero 2016; STSJ Galicia, 8 julio 2015. 
El objetivo es, pues, la protección de la relación si al concurrir causa de cese se da el supuesto de hecho de otra modalidad de interinidad. Como señalábamos, así lo han entendido algunos Tribunales contenciosos ${ }^{46}$, que abogan por la continuidad de la relación funcionarial interina, transformando su título: de sustitución a vacante. Invocan, para ello, una Jurisprudencia Social ${ }^{47}$-alumbrada cuando los Tribunales de dicho Orden conocían del contencioso del personal sanitario- según la cual no sería jurídicamente correcto el cese de personal interino de sustitución con la finalidad de que sea nombrado otro empleado público con el mismo carácter de interinidad, pues tal solución sería contraria «a la propia naturaleza de la interinidad y a los principios de interdicción de la arbitrariedad (artículo 9.3 CE ) y de la estabilidad en el empleo, aunque tal estabilidad ha de entenderse referida a la conservación del puesto de trabajo con carácter interino hasta el momento en que se produzca su cobertura definitiva u otra causa justificativa del cese. Con fundamento en la normativa mencionada cabe afirmar que la interinidad se funda en la necesidad de cubrir provisionalmente una plaza que se halla vacante, bien por corresponder a titular facultativo con derecho a reserva de la misma, bien por no hallarse cubierta aún reglamentariamente. Debe estimarse que estas situaciones son alternativas, sin que haya impedimento alguno para que una suceda a la otra, "pues la necesidad de suplencia provisional que originó el nombramiento persiste en el tiempo aunque la causa haya variado", de modo que "no resulta procedente fraccionar esta necesidad de sustituir a un titular en períodos distintos porque haya variado la causa" (STS, Sala $4 .^{a}$, de 29 de enero de 1994)» ${ }^{48}$.

\section{CONCLUSION}

Pese a la temporalidad de su relación, el funcionario interino responde estructuralmente a una necesidad institucional de la Función Pública: el desempeño de funciones públicas no permanentes por personal sometido a un régimen jurídico-administrativo que articule y pondere los derechos del empleado público con las exigencias que se deriven de tales funciones públicas.

De ahí que sea necesario erradicar la visión peyorativa del funcionario interino como un fenómeno anómalo, patológico, imperfecto o incompleto ${ }^{49}$ en el seno de la Función Pública. Por el contrario, es preciso concebirlo como un instrumento jurídico al servicio de la Administración para satisfacer necesidades temporales. No se trata de fomentar su presencia sino de entender su positiva funcionalidad para poder así regular cabalmente el régimen jurídico de los funcionarios interinos, el cual debe articular y garantizar la temporalidad que le es inherente, evitando prolongaciones de la relación desproporcionadas y abusivas, pero dotando a la relación de servicio interina de una estabilidad que impida no sólo la merma y discriminación en sus derechos sino también una precariedad en sus condiciones que haga inidónea su posición jurídica para desempeñar con eficacia, independencia y objetividad sus funciones, por muy interinas o temporales que éstas sean.

\section{REFERENCIAS BIBLIOGRÁFICAS}

BOLTAINA BOSCH, X. (2018): "Los procesos selectivos «blandos» y sus efectos sobre la profesionalización del empleo público", en Revista Vasca de Gestión de Personas y Organizaciones Públicas, número Especial 2, págs. 140-155.

BOLTAINA BOSCH, X. (2020): "La estabilización de personal temporal e interino para el 2020 con Presupuestos Generales del Estado prorrogados”, en La administración práctica: enciclopedia de administración municipal, núm. 3, págs. 47-56.

CANTERO MARTÍNEZ, J. (2017): "El funcionario interino en la jurisprudencia: sobre la necesidad de repensar la figura", en Revista Vasca de Gestión de Personas y Organizaciones Públicas, núm. 12, págs. 8-29.

FUENTETAJA PASTOR, J. A. (2018): Función Pública y Derecho europeo. Cizur Menor (Navarra): Civitas.

46 STSJ Extremadura, 22 mayo 2001 (Rec. 132/1998); STSJ Madrid, 12 enero 2002 (Rec. 1120/1998). En contra, STSJ Comunidad Valenciana, 19 enero 2001 (Rec. 1268/1997).

47 SSTS, Sala de lo Social, de 19 de mayo de 1997, 25 de octubre y 29 de enero de 1994, 21 de septiembre de 1993 y 30 de noviembre de 1992.

48 STSJ Extremadura, 22 mayo 2001 (Rec. 132/1998).

49 STSJ País Vasco, 19 julio 2002 (Rec. 369/2000): que habla de «dar plenitud a la relación jurídica, hasta entonces decididamente incompleta», de los funcionarios interinos mientras no se conviertan en funcionarios de carrera superando los correspondientes procesos selectivos. 
FUENTETAJA PASTOR, J. A. (2020): "La utilización abusiva de los funcionarios interinos ante el derecho europeo: entre la transformación en funcionarios de carrera y el derecho a indemnización", en Revista de Administración Pública, núm. 212, págs. 201-230. https://doi.org/10.18042/cepc/rap.212.07.

LÓPEZ BENITEZ, M. (2019): "Concepto y clases de empleados públicos", en IZQUIERDO, M.; LÓPEZ BENÍTEZ, M. (coords.): Derecho Administrativo. Tomo IV, pág. 57. Madrid: Tecnos.

NAVARRO NIETO, F. (2010): "Los planes de estabilización del empleo temporal en el Estatuto Básico del Empleado Público", en Temas laborales: Revista andaluza de trabajo y bienestar social, núm. 103, págs. 67-98.

PARADA VÁZQUEZ, J. R.; FUENTETAJA PASTOR, J. A. (2019): Derecho de la Función Pública, págs. 349-351. Cizur Menor (Navarra): Civitas, 2. ${ }^{a}$ ed.

ROQUETA BUJ, R. (2020): "Los procesos de estabilización del empleo temporal en las administraciones públicas" en Revista de Derecho Administrativo vLex, núm. 1, págs. 9-45.

SÁNCHEZ MORÓN, M. (2012): "Informe jurídico sobre el deber de las Administraciones Públicas de incluir en la oferta de empleo público las plazas vacantes ocupadas por personal interino o temporal y publicar en plazo las correspondientes convocatorias de selección", en Revista de Administración Pública, núm. 187, págs. 379-395.

SÁNCHEZ MORÓN, M. (2019): "La consagración del funcionario interino indefinido", en Revista de Administración Pública, núm. 208, págs. 223-238.

SÁNCHEZ MORÓN, M. (2020): Régimen jurídico de los funcionarios interinos, págs. 41-44. Cizur Menor (Navarra): Thomson Reuters Aranzadi. 